\title{
Usage of Mobile Phone by Vegetable Growers and its Impact on Vegetable Production
}

\section{Syed Mufeed Hadi Naqvi ${ }^{*}$, Badar Naseem Siddiqui ${ }^{1}$, Waqar-U1-Hassan Tareen ${ }^{1}$, Muhammad Ameer Qarib Naqvi ${ }^{2}$ and Naseeb Hussain ${ }^{3}$}

${ }^{1}$ Department of Agricultural Extension, PMAS-Arid Agriculture University Rawalpindi, Pakistan; ${ }^{2}$ Institute of Biochemistry and Biotechnology, PMAS-Arid Agriculture University Rawalpindi, Pakistan; ${ }^{3}$ Department of Plant Breeding and Genetics, Faculty of Crop and Food Sciences, PMAS-Arid Agriculture University Rawalpindi, Pakistan.

\begin{tabular}{|c|}
\hline 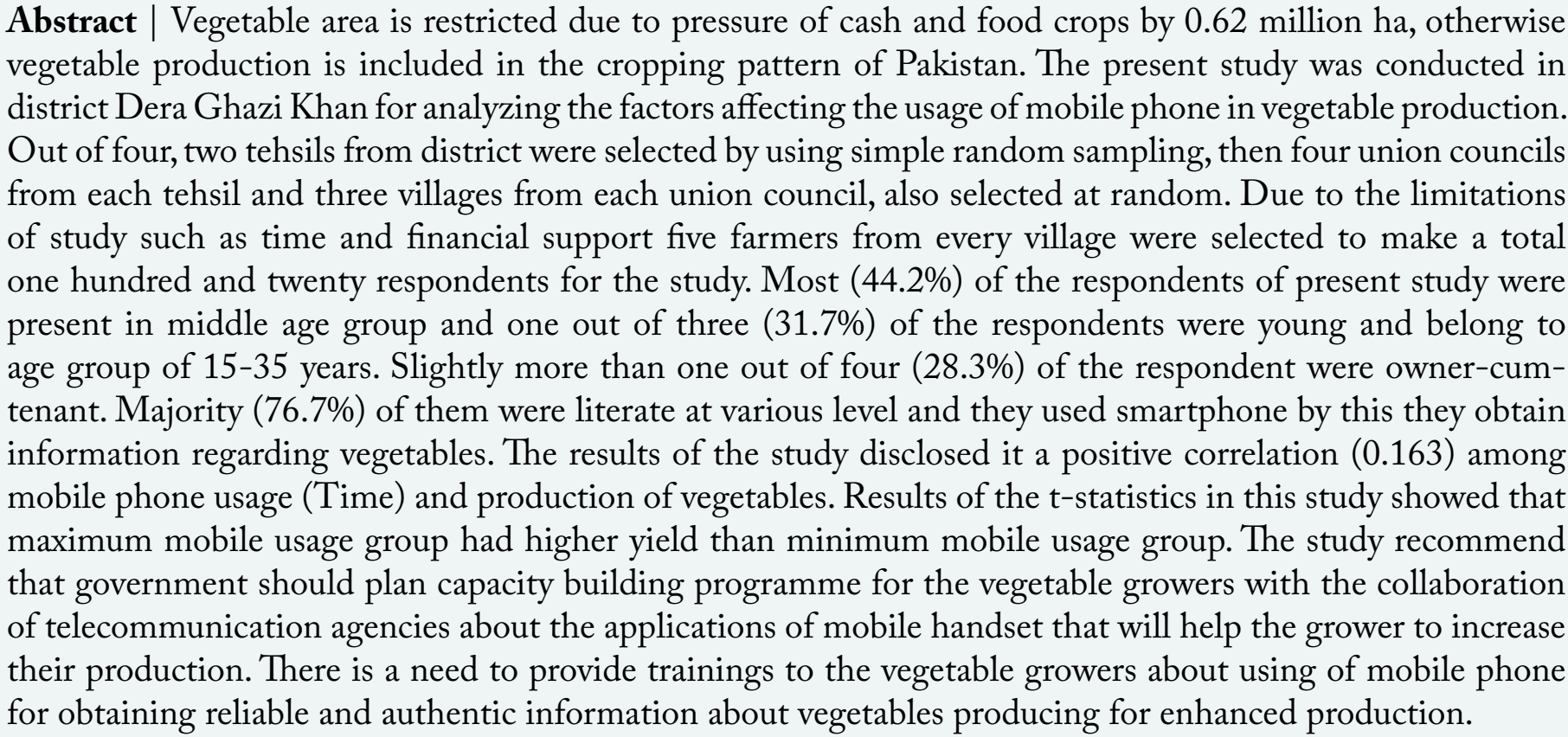 \\
\hline
\end{tabular}

\section{Introduction}

A griculture is the major strength of country's economy and play important role in the nation's development. It provides food and fiber for the individual's consumption, input for the agro-based industries and output for the export, which help in foreign exchange. World population is increasing at an alarming stage and it is expected to be doubled up to 2050 (FAO, 2009). In this scenario, for fulfilling the food demand of the entire world population it is necessary to increase the food productivity up to $70-100 \%$ (Godfray et al., 2010). In most of the countries, crop production is low due to unsuitable techniques and old methods being used in the sector of agriculture (NRC, 2011). 
Pakistan being an agricultural country depends on its production and agriculture by contributing 18.9\% to Gross Domestic Product (GDP). It also provides employment opportunity for $42.3 \%$ of the labor force in the country. More than $65 \%$ of the Pakistani population depends on agriculture for their livelihood (GoP, 2017). Old traditional methods, non-adoption of latest agricultural technologies and poor farm management are some factors that affect the productivity of agriculture (Farooq et al., 2007).

Vegetable area is restricted due to pressure of cash and food crops by 0.62 million ha, otherwise vegetable production is included in the cropping pattern of Pakistan (GoP,2018). Various vegetables are produced year round in all the provinces of Pakistan in diverse agro-ecological conditions. That's why vegetables can be grown in every season and available in the market for purchasing and selling.

The farming community of Pakistan grow more than thirty five (35) types of vegetables in various agroclimatic regions of country. Tomato, brinjal, chilies, cucumber, potato, okra and gourds are plentifully accessible during summer and spring season. Gourd, cucumber, okra, brinjal and beans are common during rainy season. Cauliflower, carrot, lettuce, coriander, spinach, onion, fenugreek, radish, cabbage, turnip, potato and peas are grown in the season of winter. For growing variety of vegetables winter season is very important (Khokhar, 2014).

Farmers in developing countries have taken advantage and combined modern technology for their activities in cultivation of agricultural crops. Mobile phone is the most important technology in this context and its benefits to farmers are more (A1-Hassan and Kwakwa, 2012).

Increase in the per capita income was observed in Peru up to $13 \%$ due to the usage of mobile phone technology. Dissemination of information by using telecommunication services has positive impact on the income of farming community (Chong et al., 2005). In Bangladesh, usage of mobile phone provides the opportunity to increase the productivity and reduce the inequality in demographics (Islam and Gronlund, 2011).

Mobile phone having ability to attach farmers to the market, bridge the information gap and enabled informed decision. Mobile phone can promote marketing, livelihoods, better production, and food security and more farmers may adopt the technology (Masuka et al., 2016). Ogunniyi and Ojebuyi (2016) claimed that mobile phone usage contributes in increasing farmer' income, reduction in transportation costs by providing the information regarding market trends and prices of crops in different markets, and increased in farm productivity. The infrastructural facilities, like electricity which should be provided to rural areas of country for enabling the farming community in effectively usage of mobile phone for agribusiness activities (Ogunniyi and Ojebuyi, 2016).

Mobile phone enable the farmers to gain information about the input and products accurate price and difference of prices in various markets of country. The farmers can obtain latest and timely information by using mobile phone as an information tool. It can help the farmers as well as market persons to reduce the communication costs and availability of wholesale market prices by using short message service (SMS) and reduce the cost of calls (Jehan et al.,2014). Mobile phone is an effective tool with compare to normal landline phone. The farmer obtains information regarding anything (disease, insect pest and seed rate etc) in the field where they want to know they just make a call to resource person (informant) but in the case of normal land line phone first the farmer goes to place where land line phone installed then make a call to resource person (informant). With the help of mobile phone farmers can watch the videos on cultural practices of crop and it is not possible with normal landline.

Mobile phone positively affects the livelihood of rural community when it is used for market-oriented farming (Mutunga and Waema, 2016). Farmers of the developing countries received many benefits by utilizing mobile phone in their agricultural business (Martin and Abbott, 2010). The farming community can obtain information for implementation of decision based precision agriculture by using the Global Positioning System (GPS) and mobile mapping facilities of mobile phone (Michailidis et al., 2010). Mobile phone can provide a platform to farmer for getting and sharing information about agriculture. Farmers nowadays use mobile phone for multipurpose (Murthy, 2009).

There is less use of latest IT and ICTs in vegetable development in our country. Most of the developed and some developing countries have taken its 
advantage in agriculture sector by providing timely, swift and accurate information to farmers for boosting their income and improving livelihood. In Pakistan in general, and particularly in district Dera Ghazi Khan no effort has been carried out in this regard which is a need to conduct research on probable agricultural use of mobile phone technology by the farmers in order to get in time information related to vegetable production technology. The study was conducted on the objectives a) analyzing the demographics of vegetables growers, b) effect of usage of mobile phone on vegetable production.

\section{Materials and Methods}

The present study was grounded on first hand data, collected through random sampling techniques using interview schedule in district Dera Ghazi Khan. The districts comprises four tehsils namely, Dera Ghazi Khan, Kot Chutta, Taunsa Sharif and Tribal area. Two tehsils (Dera Ghazi Khan, Kot Chutta) were selected on the basis of area under vegetables. Twelve (12) villages were than selected from each tehsil by random sampling. Sample of one hundred and twenty (120) vegetable growers were selected. Interview schedule was designed for the purpose of collection of data. The interview schedule was pre-tested on 15 respondents. Pre testing was performed to update the interview schedule and mold the question with the response of defendants of the study and for the obtaining knowledge which kind of questions provide to required information based on the objectives of the research, which was primarily done in the area of Kot Chutta. The interview schedule was furnished after making necessary changes according the results of pre-testing. Data was analyzed by using Statistical Package for Social Sciences (SPSS) version 22.0.

Difference of productivity were analyzed through independent t-test. Treating the difference as random sample from a normal population with mean $\mu \mathrm{D}=$ $\mu \max -\mu \min$ and unknown standard deviation $\sigma \mathrm{D}$ one sample $\mathrm{t}$-test was performed on them (Jehan et al., 2014).

The testing hypothesis procedure for independent t-test is given as under:

Testing hypothesis $\mathrm{H}_{\mathrm{o}}$ : $\mu \max =\mu \min$ (No difference in the production of both groups)

And the alternative is $\mathrm{H}_{1}: \mu \max \neq \mu \min$ (Production of max. group are not equal than min. group)
Test statistics

$$
t=\frac{\bar{d}}{s_{d} / \sqrt{n}}
$$

with $v=n-1$ degrees of freedom at 0.05 significant level.

\section{Results and Discussion}

\section{Demographic characteristics}

Demographic information provides facts about respondents of study. The major purpose of analyzing the demographics is that by this we examine the characteristics of the representative sample of the target population (Salkind, 2010). Demographic characteristics such as age, education, tenancy status, to hold land and sources of agricultural information etc.

\section{Age}

Age of the person directly affect upon the person's attitude toward his work, observation, how he tackle the situation, ideas of a person about things and his experience about the things (Rajan, 1991). Age is the number of years that an individual spend during his life span from birth to death or any date (Hashmi et al., 2007). The results indicate that most (44.2\%) of the respondents of study were present is the group of middle aged and one out of three $(31.7 \%)$ of the respondents of study were young and belong to age group of 15-35 years (Table 1). Results of this study are slightly similar with Adeel (2015) who conducted study on working efficiency of extension field staff with regard to IPM of cotton in district D. G. Khan and reported that most (41.7\%) of the respondents of his study were middle aged.

Table 1: Age of the respondents.

$\begin{array}{lll}\text { Age (years) } & \text { F } & \mathbf{\%} \\ \text { Young (15-35) } & 38 & 31.7 \\ \text { Middle age (36-45) } & 53 & 44.2 \\ \text { Old age (46-65) } & 29 & 24.1 \\ \text { Total } & 120 & 100.0\end{array}$

\section{Tenancy status}

The way of cultivation of land are referred as the tenancy status of the farmer or individual. In this context, tenancy status is divided in three major categories that are tenant, owner and owner-cumtenant. The results show that fair majority (58.3\%) of the respondents were owner of their agricultural land (Table 2). The results further indicate that slightly more than one out of four $(28.3 \%)$ of the respondent were owner-cum-tenant. Mastane and Oyekale (2014) conducted study on factors affecting 
marketing of vegetables among small scale farmers in Mahikeng Local Municipality, North West province, South Africa, who reported contradictory results of their study by arguing that $42.6 \%$ of the respondents had ownership rights on their land.

Table 2: Tenancy status of the respondents.

$\begin{array}{lll}\text { Tenancy } & \text { F } & \mathbf{\%} \\ \text { Owner } & 70 & 58.3 \\ \text { Tenant } & 16 & 13.3 \\ \text { Owner-cum-tenant } & 34 & 28.3 \\ \text { Total } & 120 & 100.0\end{array}$

\section{Educational qualification}

Education was considered as the formal year of attending schooling. Data in Table 3 showed that and one-fourth (23.3\%) of the respondents were illiterate. Furthermore, more than half $(55.0 \%)$ of the respondents obtained education up to middle. Results of the study illustrate that near about one-fifth (21.7\%) of the respondents got education matric and above than matric. Results are slightly different than that of Adeel (2015) conducted study on working efficiency of extension field staff with regard to IPM of cotton in district D. G. Khan, whose majority (80.8\%) of the respondents were educated. Results of the study are similar with Nazari and Hassan (2011) conducted study on the role of television in the enhancement of farmers' agricultural knowledge, whose majority $(77 \%)$ of the respondents were educated.

Table 3: Education of the respondents.

$\begin{array}{lll}\text { Education } & \text { F } & \mathbf{\%} \\ \text { Illiterate } & 28 & 23.3 \\ \text { Up to Middle } & 66 & 55.0 \\ \text { Matric and above } & 26 & 21.7 \\ \text { Total } & 120 & 100.0\end{array}$

\section{Size of land holding}

Size of land holding is important factor. The land cultivated by an individual or his family are referred as size of land holding (Nawaz, 1989) he also discussed that larger size of land enhance the adoption of agricultural innovations. The data about land holding of the respondents are presented in Table 4. The results revealed that most $(55.8 \%)$ of the respondents of the study was small land holders having land up to 12.5 acres. Furthermore, results shows that one out of five (20.8\%) of the respondents of study had medium land holding while one-fifth $(23.3 \%)$ of the respondents were large farmers holding land above 25 acres. majority $(76.7 \%)$ of the respondents were literate

Results are slightly different with Aziz et al. (2018) conducted study on the relationship between socioeconomic aspects of farmers and their awareness and adoption of short agricultural messages telecast on PTV. Study was conducted in Naseerabad district of Baluchistan. According to their study about one out of four $(23.33 \%)$ of the defendants of study were the medium farmers.

Table 4: Land holding of the respondents.

$\begin{array}{lll}\text { Land holding (acre) } & \text { F } & \text { \% } \\ \text { Small } & 67 & 55.8 \\ \text { Medium } & 25 & 20.8 \\ \text { Large } & 28 & 23.3 \\ \text { Total } & 120 & 100.0\end{array}$

Small: Up to 12.5 acres; Medium: 12.6-25 acres; Large: More than 25 Acres.

Correlation analysis of mobile phone used (Time) and production

Results of the study indicate that there was moderate and positive correlation of 0.163 among mobile phone used (Times) and production of vegetables ( $\mathrm{Kg}$ per acre).

\section{Correlation analysis of demographics with Production of vegetables}

Correlation analysis performed for checking the significant level and relationship between production of vegetables and demographic characteristics like age, annual income, education and tenancy status of respondents. The results of the analysis are presented in Table 5. Results of study revealed that there was negative correlation of -0.099 between average annual income and age. It is also shows that there is highly positive correlation of 0.452 between education and average annual income. The results of the study disclosed the positive and highly significant correlation between production of vegetables and education. Furthermore, results showed negative but significant correlation between production of vegetables and tenancy status of the farmer.

Table 5: Correlation of Production of vegetables with demographics.

$\begin{array}{lllllll}\text { Age } & 1 & & & & \\ \text { Average annual income } & -.099 & 1 & & & \\ \text { Education } & -.022 & .452^{* *} & 1 & & \\ \text { Tenancy } & -.073 & -.156 & -.106 & 1 & \\ \text { Production of vegetable } & .015 & .117 & .370^{* *} & -.302^{* *} & 1 \\ \text { * Correlation is significant at the } 0.01 \text { level (2-tailed). } & & \end{array}$

September 2020 | Volume 36 | Issue 3 | Page 903 
Comparative analysis of mobile phone usage and production

Usage of mobile phone two to three times in a day for obtaining information regarding vegetable production technology or related information was set as threshold level for the classification of farmers into two groups. Farmers who used more than two to three times in a day for the purpose of obtaining information regarding vegetables production technology and improved techniques were placed in maximum usage group while the remaining were placed in minimal group. The results revealed that maximum usage group had higher yield than minimum usage group. The results computed by $\mathrm{t}$-test at $95 \%$ confidence interval indicate that yield of maximum usage group is higher so it accept the alternative hypothesis (Table 6). Results are similar with Jehan et al. (2014) who conducted study on usage of mobile phones by farming community and its impacts on vegetable productivity. The study area of their research was Charasdda district of Khyber Pakhtunkhwa province of Pakistan. The null hypothesis of their study was that, there is no difference in the productivity of maximum usage hours and minimum usage hours. Their findings also rejected the null hypothesis and found that the group that maximum used mobile phone for obtaining information regarding vegetable production had the higheryield than the group who used mobile minimum for information purpose.

Table 6: Comparative analysis of mobile phone usage and production of vegetables.

$\begin{array}{lll}\text { Variables } & \text { Mean } \pm \text { S.E. } & \text { Standard deviation } \\ \text { Max } & 1446.25 \pm 102.28993 & 409.15971 \\ \text { Min } & 1272.0385 \pm 34.72135 & 354.08967 \\ \text { Diff } & 174.2115 \pm 63.56858 & 55.07004\end{array}$

t: 38.855; Observations: 120; df: 119; $\operatorname{Pr}(T>t): 0.0002$

\section{Conclusions and Recommendations}

It is concluded that most of the respondents of the study were middle aged and they were interested in growing vegetable. They had their own agricultural land and majority of them were educated. Furthermore, it is concluded that positive and moderate correlation were observed between mobile phone usage (time) and production of vegetables ( $\mathrm{kg}$ per acre). It is also concluded that maximum mobile phone usage group had higher yield than minimum mobile usage group.

On the basis of above conclusion, the study would recommend:
- Government should plan capacity building programs for the vegetable growers with the collaboration of telecommunication agencies about the mobile phone application that will help the grower to increase their production.

- There is a need to provide trainings to the vegetable growers about using mobile phone for obtaining reliable and authentic information about vegetables producing for enhanced production.

\section{Novelty Statement}

The study presents the useful policy implications by highlighting the gap in using of telecommunication gadgets for obtaining information among the farming community who produced vegetable in D.G Khan, Punjab. Moreover, this article highlight the effects of mobile phone usage for information.

\section{Author's Contribution}

Syed Mufeed Hadi Naqvi: Collection, compilation, analysis and summarization the research work.

Badar Naseem Siddiqui: Supervised all the work.

Waqar ul Hassan Tareen: Helped in compiling the results.

Ameer Qarib and Naseeb Hussain: Helped in data collection.

\section{Conflict of interest}

The authors have declared no conflict of interest.

\section{References}

Adeel, M., 2015. Working efficiency of extension field staff with regards to IPM of cotton in district D. G. Khan. M.Sc. (Hons.) thesis. Dep. Agric. Ext. Commun. PMAS-Arid Agric. Univ. Rawalpindi, Pakistan.

Al-Hassan, H. and P.A. Kwakwa. 2012. The use of mobile phones by small scale farmers in Northern Ghana: Benefits and challenges. J. Entrep. Manage., 1(3): 40-46.

Aziz, R., B.N. Siddiqui, J. Ali, A. Ali, S. Fahmid, Q. Raza and M.A.A. Akram. 2018. Relationship between socio-economic aspects of farmers and their awareness and adoption of short agricultural messages telecast on PTV. Int. J. Adv. Res. Biol. Sci., 5(1): 25-32.

Chong, A., V. Galdo and M. Torero. 2005. Does privatization deliver? Access to telephone 
services and household income in poor rural areas using Quasi-Natural experiment in Peru. Inter-Am. Dev. Bank Working Paper No. 535. Washington, DC, USA. https://doi. org/10.2139/ssrn.1818735

Farooq, S., S. Muhammad, K. Chaudhary and I. Ashraf. 2007. Role of print media in the dissemination of agricultural information among farmers. Pak. J. Agric. Sci., 44(2): 378380.

FAO. 2009. Global agriculture towards 2050. High level expert forum how to feed the world in 2050: Food and Agriculture Organization (United Nations) Rome. Available at: http://www.fao. org/fileadmin/templates/wsfs/docs/Issues_ papers/HLEF2050_Global_Agriculture.pdf

Godfray, H.C.J., J.R. Beddington, I.R. Crute, L. Haddad, D. Lawrence, J.F. Muir and C. Toulmin. 2010. Food security: The challenge of feeding 9 billion people. Science. 327: 812-818. https://doi.org/10.1126/science.1185383

GoP.2017. Economic survey of Pakistan, Economic Advisor's Wing, finance division, Islamabad, Pakistan.

GoP. 2018. Emerging Pakistan. Ministry of Commerce, Islamabad, Pakistan. Availabe at: https://www.emergingpakistan.gov.pk/sectors/ vegetables/. Accessed on: 29 August, 2018.

Hashmi,A.H.,A.A.Maann, K.Asghar and M.Riaz. 2007. Gender role in livestock management and their implication for poverty reduction in rural Toba Tek Singh, Punjab-Pakistan. Pak. J. Agric. Sci., 44(4): 674-678.

Islam, S.M. and A.G. Gronlund. 2011. Factors influencing the adoption of mobile phone among the farmers in Bangladesh: Theories and practices. Int. J. Adv. ICT Emerg. Reg., 4(1): 4-14. https://doi.org/10.4038/icter.v4i1.4670

Jehan, N., K. Mahmood, A. Muhammad, S. Abid, M. Hussain, Z.M. Khan and B. Ahmed. 2014. Use of mobile phones by farming community and its impact on vegetable productivity. Pak. J. Agric. Res., 27(1): 58-63.

Khokhar, M., 2014. Production status of major vegetables in Pakistan, their problems and suggestions. Agric. Corner, pp. 9.

Martin, B. and E. Abbott. 2010. Development calling: the use of mobile phones in agriculture development in Uganda. Int. Fed. Inf. Process. Techn. Comm.,
Masuka, B., T. Matenda, J. Chipomho, N. Mapope, S. Mupeti, S. Tatsvarei and W. Ngezimana. 2016. Mobile phone use by small scale farmers: A potential to transform production and marketing in Zimbabwe. South Afr. J. Agric. Ext., 44(2): 121-135. https://doi. org/10.17159/2413-3221/2016/v44n2a406

Matsane, S.H. and A.S. Oyekale. 2014. Factors affecting marketing of vegetables among small scale farmers in Mahikeng Local Municipality, North West province, South Africa. Mediterr. J. Soc. Sci., 20(5): 390-397. https://doi. org/10.5901/mjss.2014.v5n20p390

Michailidis, A., E. Loizou, S. Nastis and K. Mattas. 2010. August 25-27. Mobile Telephony as a change driver in rural areas. Pap. Present. $118^{\text {th }}$ semin. Eur. Assoc. Agric. Econ., Ljubljana, Slovenia.

Murthy, C., 2009. Use of convergent mobile technologies for sustainable economic transformation in the lives of small farmers in rural India. Turkish Online J. Distance Educ., 10(3): 32-41.

Mutunga, I.M. and T.M. Waema. 2016. Context of mobile phone use and its effect on smallholder farmers' livelihood outcomes in Kenya. Int. J. Sci. Res. Innov. Technol., 3(4): 19-25.

Nawaz, M., 1989. Farmers perception of the working of extension field staff in Jhang district. M.Sc. (Hons.) thesis, Dep. Agric. Ext., Inst. Agric. Ext. Rural Dev., Univ. Agric. Faisalabad, Pakistan.

Nazari, M.R. and M.S.B.H. Hassan. 2011. The role of television in the enhancement of farmers' agricultural knowledge. African J. Agri. Res., 6(4): 931-936.

NRC. 2011. Toward sustainable agricultural systems in the $21^{\text {st }}$ century. Natl. Acad. Press, Washignton. DC, USA.

Ogunniyi, M.D. and B.R. Ojebuyi. 2016. Mobile phone use for agribusiness by farmers in Southwest Nigeria. J. Agric. Ext., 20(2): 172187. https://doi.org/10.4314/jae.v20i2.13

Rajan, S.K., 1991. Determination of new strategies for improving wheat production in Loralai, Balochistan. M.Sc. (Hons.) thesis, Dep. Agric. Ext. Univ. Agric. Faislabad, Pakistan.

Salkind, N.J. (ed.). 2010. Encyclopedia of research design., SAGE Publishers, Inc. California, USA. https://doi.org/10.4135/9781412961288 